\title{
A SAÚDE DA CRIANÇA EM CONTEXTO DE POBREZA E DE EXCLUSÃO - NOVOS DESAFIOS DE POLÍTICAS DE INCLUSÃO
}

\section{La santé de l'enfant dans le contexte de la pauvreté et d'exclusion - de nouvaux défis en politiques d'inclusion}

Natália Ramos ${ }^{1}$

\section{Resumo}

São apresentados e analisados, de forma sumária, alguns indicadores e fatores que nos países em desenvolvimento e desenvolvidos estão na origem e no aumento de situações de pobreza, exclusão e violência, provocando disfuncionamentos sociais, familiares, psicológicos e somáticos, com graves conseqüências para a saúde, educação e qualidade de vida dos indivíduos, em particulardas crianças e das famílias. Apresentam-se, igualmente, algumas reflexões e estratégias, tendo em vista a promoção de políticas de inclusão. Palavras-chave: Pobreza; Exclusão; Violência; Educação.

\section{Résumé}

Ce sont présentés et analisés de façon résumé quelques indicateurs et éléments que dans les pays en développement et aussi ceux developpés sont aussi à l'origine et à l'augmentation des situations de pauvreté, d'exclusion et de violence. Cela détermine des problèmes sociaux, familiers, psychologiques, et somathiques menant à de graves conséquences pour la santé, l'éducation et la qualité de vie des individus, particulièrement des enfants et des familles. Ce sont aussi présentés égalementquelques réflexions etstratégies objectivant la promotion de politiques d'inclusion.

Mots-clefs: Pauvreté; Exclusión; Violence; Éducation.

1 Professora e Investigadora na Universidade Aberta de Lisboa, Centro de Estudos das Migrações e das Relações Interculturais, CEMRI, Lisboa. Diretora do Mestrado em Comunicação em Saúde da Universidade Aberta de Lisboa. Correio Eletrônico: natpramos@hotmail.com 


\section{Introdução}

As novas problemáticas individuais e grupais que vêm se registrando nas sociedades contemporâneas, nos diferentes países e continentes, colocam novas questões e desafios à sociedade em geral, às diferentes instituições, às políticas educativas, sociais e de saúde, as quais terão de fazer face, de uma forma articulada, às necessidades criadas pelas novas realidades sanitárias, familiares, educativas, culturais e socioeconômicas, pelas novas configurações no campo social, da educação e da saúde, pelo número crescente de populações migrantes e refugiadas que afluem às cidades e países industrializados, pelo aumento da precariedade e das novas formas de exclusão.

Estas problemáticas exigem abordagens teóricas e interventivas, multidimensionais e pluridisciplinares, capazes de promover e harmonizar a saúde e a educação com o bem-estar social e psicológico dos indivíduos, das famílias e dos grupos, maioritários ou minoritários, autóctones ou migrantes; implicam um modelo holista da saúde que considere o indivíduo na sua totalidade e complexidade, nas suas dimensões social, psicológica, cultural e biológica, ou seja, coletiva e individual e a saúde como um processo de desenvolvimento que ocorre num dado contexto sociocultural, familiar e comunitário e que se processa ao longo da vida do indivíduo.

Para a OMS, a saúde é um estado de completo bem-estar físico, mental e social e não simplesmente a ausência de doença ou incapacidade. A saúde é, como defende este organismo, "um dos direitos fundamentais de todo o ser humano, sem distinção de raça, religião, opiniões políticas e condição econômica e social" (OMS, 1948). No entanto, este direito à saúde e a Declaração de Alma Ata (OMS, 1978), protagonizando um modelo de sistema de saúde assegurando uma cobertura universal, a saúde para todos no ano 2000 e uma esperança de vida à nascença de 60 anos são objetivos que não foram ainda completamente realizados.

\section{Criança, Família e Sociedade}

O desenvolvimento da criança, a sua socialização e saúde, o tipo de cuidados e de proteção que lhe são prestados, próprios de cada época e de cada grupo social e cultural, são influenciados pelas tradições culturais, pelas representações, crenças, etnoteorias, que os adultos têm sobre as necessidades, a saúde e a natureza da criança, sobre os seus ritmos de desenvolvimento e as formas de cuidar e educar, mas, também, pelas condições ecológicas, socioeconômicas e políticas, pelas condições de vida da família nomeadamente, condições sociais, habitacionais, trabalho dos pais, particularmente da mãe, 
densidade familiar, equipamentos sanitários, escolares e sociais. As crianças e as famílias estão inseridas em meios culturais, físicos, sociais e econômicos específicos, em diferentes "nichos ecológico-culturais e de desenvolvimento". As características e acontecimentos que ocorrem nestes nichos influenciam direta ou indiretamente as crianças e as famílias, o seu desenvolvimento, educação e saúde, o bem-estar e qualidade de vida tanto das crianças como das famílias, as competências educativas e comunicacionais dos pais e o trabalho de parceria e de co-responsabilização (WHITING, 1975; BERRY, 1976, 1992; BRONFENBRENNER, 1979; OGBU, 1981; SUPER, HARKNESS, 1986, 1997; GABARINO, 1992; RAMOS, 1993, 1998, 1999, 2001, 2002).

Na sociedade contemporânea, a transformação e a evolução das concepções e valores socioculturais e familiares, das novas condições sociais, nomeadamente familiares, com um aumento crescente de famílias nucleares e monoparentais, as quais deverão assegurar as responsabilidades e cuidados partilhados outrora pela família alargada e redes comunitárias, como ainda, o aumento do trabalho feminino, da fragilidade do trabalho/emprego, da violência familiar, das separações e rupturas familiares, sociais e culturais, têm conduzido a novos papéis familiares, a novas formas de socialização e educação da criança, a separações precoces e bruscas da criança do seu ambiente familiar e social, a disfunções psicológicas, sociais e familiares, a novas formas de exclusão e violência, vindo a aumentar as situações de vulnerabilidade, de risco social, psicológico e biológico para as crianças (SHORTER, 1977; ANTHONY et al., 1982, 1983; BOURGUIGNON et al., 1985; SINGLY, 1993; BIFULCO, MORAN, 1998; LANGOUET, 1998; RAMOS, 1993, 1998, 1999, 2001, 2002). Com efeito, em todo o mundo, os riscos para o desenvolvimento, saúde e bem-estar das crianças e das famílias estão a aumentar. Segundo o Fundo das Nações Unidas para a Infância - UNICEF (2001, 2002) e a Organização Mundial de Saúde - OMS (2002), apesar de na última década do século XX (1990-2000) se ter registrado uma redução anual de três milhões quanto ao número de crianças mortas com menos de cinco anos de idade, esta década trouxe muita ruptura, violência e precariedade à criança e às suas condições de vida, vindo aumentar os riscos para a saúde física e mental, devido à intensificação da pobreza, à disparidade crescente entre países ricos e pobres e no interior do mesmo país, ao aumento da morte e da doença ligada ao VIH/SIDA, sobretudo na África subsaariana, ao aumento da violência familiar e social, ao isolamento de um número crescente de indivíduos e famílias e ainda ao aumento do terrorismo e dos conflitos armados.

Nascer, crescer, viver em situação de pobreza, de guerra, de migração, de doença, constitui um risco, um trauma e um desafio para a criança e a sua família. 


\section{Desenvolvimento, Pobreza e Exclusão}

No que diz respeito às situações de pobreza e exclusão, estas apontam para a existência de múltiplos fatores de risco que afetam o desenvolvimento e a saúde da criança, constituindo o desenvolvimento humano e social, a educação/escola e a família suportes básicos contra a exclusão social. No século 20, muito embora se tivesse verificado um grande crescimento econômico e uma melhoria das condições de vida em geral, as desigualdades, a exclusão e a pobreza também se intensificaram, sendo esta vizinha da abundância, sobretudo nos países em desenvolvimento.

A pobreza priva o indivíduo, em particular a criança, dos seus direitos fundamentais, nomeadamente, saúde, nutrição, educação e proteção contra as diversas formas de violência, maus-tratos, exploração e discriminação.

A pobreza, nas suas diferentes formas, tem vindo a aumentar em todo o mundo, nos países em desenvolvimento, como nos países desenvolvidos, reunindo um conjunto de déficits econômicos, culturais e sociais e exigindo uma abordagem multidimensional e pluridisciplinar. Como refere Dubois (2001), a pobreza tem de ser analisada de uma forma plural e, por isso, temos de considerá-la nas suas diferentes dimensões:

- A pobreza monetária, resultando de uma insuficiência de recursos que origina um consumo de bens insuficientes;

- A pobreza das condições de vida ou de existência representando a impossibilidade de satisfazer algumas das necessidades fundamentais e traduzindo-se, nomeadamente, por um déficit em matéria de alimentação, de saúde, de escolarização, de alojamento;

- A pobreza das potencialidades ou das capacidades que provém do fato de que não foi possível constituir-se um capital suficiente para tirar proveito das capacidades individuais.

Estas duas últimas formas de pobreza podem ser reagrupadas na noção de "pobreza humana", introduzida pelo Programa das Nações Unidas para o Desenvolvimento Humano em 1997 (PNUD, 1997) e definida como a privação de certas ou de todas as potencialidades humanas de um indivíduo: ter uma vida longa, saudável e criativa, instruir-se, beneficiar-se de um nível de vida digno e do respeito de si e dos outros.

Vamos destacar alguns indicadores que nos parecem importantes para compreender a relação entre o desenvolvimento, a pobreza e a saúde/ doença e mortalidade.

No planeta, quase metade dos habitantes vive com menos de 2 dólares por dia e um quinto tem menos de 1 dólar por dia. Por exemplo, na América Latina, 15\% da população vive com menos de um dólar por dia (BM, 2000). Também, no Brasil, o Instituto Brasileiro de Geografia e Estatística (1991) 
indicava que, em 1990, 53,5\% das crianças e adolescentes viviam em famílias cujos recursos por mês eram inferiores a 50 dólares.

Nos países em desenvolvimento, entre os diferentes indicadores exprimindo a pobreza existencial, a taxa de população privada de água potável é a mais inquietante (1.213 milhões de pessoas), seguida da taxa de adultos analfabetos (842 milhões) e da população privada de serviços de saúde (766 milhões). Este déficit de acesso aos serviços de saúde traduz-se por um risco elevado de morte antes dos 40 anos, implicando para o conjunto dos países em desenvolvimento 507 milhões de pessoas (PNUD, 1997).

A África Subsaariana e a Ásia do Sul são as regiões mais tocadas pela pobreza, com respectivamente 46 e 40 pessoas em 100 vivendo em situação de pobreza. Vêm em seguida a América Latina e as Caraíbas com 16\%, a Ásia de Leste e o Pacífico com 15\%, a Europa e a Ásia Central com 5\% e os Países Árabes com 2\% (BM, 2000).

Na União Européia, são cerca de 17 milhões de crianças que vivem em situação de pobreza, isto é, uma criança em cada cinco com idade inferior a 18 anos. Este número tende a aumentar nos próximos anos. Por exemplo, em Portugal, 21\% da população vive em situação de pobreza, ou seja, vive com rendimentos mensais abaixo dos $60 \%$ relativamente à média nacional, figurando Portugal no 23ํ lugar num conjunto de 175 países. Portugal apresenta a maior disparidade da União Européia entre ricos e pobres, auferindo os primeiros 6,4 vezes mais do que os segundos. Dez por cento da população mais rica do país têm rendimento quinze vezes superior aos dez por cento mais pobres, números que colocam Portugal no primeiro da lista dos países da UE onde se registra a maior desigualdade entre ricos e pobres (RELATÓRIO DE DESENVOLVIMENTO HUMANO DAS NAÇÕES UNIDAS, 2003).

Nos EUA, aproximadamente $25 \%$ de crianças com menos de seis anos nasceu em ambiente de pobreza (HUSTON et al. 1994).

Importa salientar que na maioria dos países em desenvolvimento, é a pobreza e as desigualdades sociais que mais afetam a saúde e a educação.

\section{Pobreza, Saúde e Educação}

Como refere a OMS (1995):

A pobreza é o crime mais desumano e é o maior fator de sofrimento em todo o mundo. È a principal causa da diminuição da esperança de vida, da incapacidade e da fome. A pobreza é um fator de risco importante para as doenças mentais, para o stresse, para o suicídio, para a desintegração familiar e para o abuso de substâncias. Atualmente, para muitos indivíduos em todo 
o mundo, o caminhar da infância até à velhice é acompanhado pelas sombras gêmeas da pobreza e da injustiça e pelo duplo fardo do sofrimento e da doença.

A pobreza e a degradação das condições sociais e habitacionais das famílias têm influência na saúde das crianças e estão na origem de várias patologias. Na França, desde há alguns anos que são diagnosticados casos de saturnismo (intoxicação pelo chumbo), tornando-se esta infecção um problema de saúde pública e tocando, sobretudo, as crianças pequenas que vivem em habitações insalubres expostas ao chumbo. Assim, entre maio de 1992 e outubro de 1995, 35\% das 8.218 crianças despistadas como crianças em risco, estavam intoxicadas sofrendo de saturnismo (RAZKALLAH et al., 1997).

Também nos EUA, cerca de 1,7 milhão de crianças em idade préescolar vive em situações habitacionais precárias, sofrendo níveis de exposição ao chumbo susceptíveis de colocar em risco o seu desenvolvimento e saúde (BRODY et al., 1994).

A pobreza afeta profundamente o potencial de desenvolvimento físico e psíquico da criança, podendo deixar marcas irreversíveis no seu desenvolvimento e conduzir à morte. Em média, uma criança originária de uma família fazendo parte das $20 \%$ mais pobres da população mundial corre, pelo menos, duas vezes mais riscos de morrer antes dos cinco anos, relativamente a uma criança originária de uma família fazendo parte das $20 \%$ mais ricas, compensando as famílias pobres esta taxa mais elevada de mortalidade, por uma taxa de fecundidade mais elevada (UNICEF, 2001).

Um nível de mortalidade excessiva revela-se como uma das expressões da pobreza. As regiões da África Subsaariana e da Ásia do Sul são as mais pobres e as que têm as mais elevadas taxas de mortalidade, nomeadamente, mortalidade infantil, materna e geral (esperança de vida ao nascimento) como indicam os seguintes números (BM e PNUD, 2000):

- Africa Subsaariana: Mortalidade infantil (1998) (92 por 1000 natos vivos); Mortalidade Materna (1995) (975 por 100.000 natos vivos);

Esperança de vida (1995-2000) - 48, 9;

- Ásia do Sul: Mortalidade infantil (1998) - 119; Mortalidade Materna (1995) - 551;

Esperança de Vida (1995- 2000) - 62, 7.

Muito embora se tenha verificado no mundo uma diminuição importante da taxa de mortalidade, devido ao desenvolvimento dos serviços de saúde e educativos, à política alimentar, ao melhoramento do contexto ambiental (qualidade da água, higiene pública, conforto habitacional) outros fatores têm vindo abrandar esta baixa de mortalidade, nomeadamente, as crises políticas e os conflitos armados, o desenvolvimento de certas doenças emer- 
A saúde da criança em contexto de pobreza e de exclusão - novos desafios de políticas de inclusão

gentes (VIH/SIDA e hepatite B) e a fraca adequação dos sistemas de cuidados de saúde.

A má nutrição é uma outra componente da pobreza humana. Ainda hoje, apesar dos esforços e avanços registrados, avalia-se em 158 milhões 0 número de crianças com menos de cinco anos que nos países em desenvolvimento sofrem de má nutrição grave, isso estando na origem de grande mortalidade infantil (UNICEF, 2001). No conjunto dos países em desenvolvimento, $31 \%$ das crianças de menos de 5 anos sofrem de baixo peso e esta proporção atinge $40 \%$ nos países menos desenvolvidos e $49 \%$ na Ásia do Sul. Igualmente e associado a fatores culturais e socioeconômicos, mais de metade das africanas e asiáticas sofrem de carências graves alimentares, que afetam particularmente a saúde das mulheres grávidas e os recém-nascidos. Por exemplo, em muitas comunidades, para além do hábito das mulheres servirem primeiro os homens e as crianças, devendo contentar-se com os restos alimentares, o que resulta numa insuficiência alimentar quantitativa e qualitativa, nomeadamente em ferro e proteínas e em anemias, existe igualmente a crença de que os meninos necessitam de uma maior quantidade de alimentos que as meninas.

Também as crianças, nos países em desenvolvimento, estão mais sujeitas, para além da má nutrição, a infecções respiratórias, paludismo, diarréia, rubéola, carência de iodo, as quais afetam o absentismo e os resultados escolares e estão na origem de um grande número de mortes de crianças com menos de 5 anos, registrando-se, anualmente, perto de 11 milhões de mortes destas crianças nestes países (MARTINETTI, 2002).

A Ásia do Sul e de Leste e, sobretudo, a África Subsaariana, caracterizam-se por uma situação muito grave, onde a privação de acesso aos equipamentos de saúde, o analfabetismo, a má nutrição e os riscos de morte se acumulam e multiplicam. Cabe destacar que, em 1999, Angola era o segundo país do mundo com a mais alta taxa de mortalidade de crianças com menos de 5 anos (UNICEF, 2002). Também na Ásia do Sul e no Próximo e Médio Oriente, há uma submortalidade das meninas com menos de 5 anos, devido também a fatores culturais. A preferência dada aos meninos origina uma insuficiência de cuidados e de alimentação às meninas, cujo estado de saúde se deteriora.

Nos países em desenvolvimento, apesar de nas últimas décadas a taxa de vacinação contra as principais doenças evitáveis ter passado de $5 \% \mathrm{em}$ 1974 para 80\% em 2002, ainda hoje mais de 2 milhões de crianças de menos de cinco anos continua a morrer anualmente de seis doenças evitáveis pela vacinação: rubéola, difteria, coqueluche, tuberculose, poliomielite e tétano (MARTINETTI, 2002). Igualmente, dois terços das crianças que morrem em cada ano são recém-nascidos, sendo as suas mortes devidas a causas que provocam também a morte das mães, como sejam cuidados obstétricos inade- 
quados ou inexistentes, falta de acompanhamento durante a gravidez e parto, dificuldades de acesso aos serviços médicos de emergência quando surgem complicações e más condições de higiene. Para além disso, os recém-nascidos estão expostos a certos riscos, como insuficiência de cuidados básicos, infecções e lesões obstétricas e problemas ligados à prematuridade (UNICEF, 2000).

Uma grande parte das mortes de crianças com menos de cinco anos que ocorre anualmente no mundo poderia ser evitada, proporcionando às famílias, particularmente às mães e às crianças, melhores condições de saúde e melhores condições educativas e socioeconômicas. Com efeito, a saúde e bem-estar das crianças está estreitamente ligada à saúde e bem-estar das mães, refletindo, em grande parte, a mortalidade infantil e materna o nível de educação e as condições socioculturais e de vida das mães e o acesso destas aos cuidados de saúde, nomeadamente, ao planejamento familiar e à contracepção.

A falta ou déficit de acesso aos serviços e cuidados de saúde traduzse por uma taxa geral de mortalidade materna particularmente elevada, a situação sendo mais grave nos países menos desenvolvidos e na África Subsaariana (perto de mil mortes de mães por 100.000 nascimentos em 2000, a África e a Ásia concentrando 95\% destas mortes. A OMS (2000) destacava a mortalidade materna em Moçambique como sendo particularmente preocupante, 1.100 mulheres por 100.000 habitantes, indicando este país como um dos países mais afetados do mundo por este problema. Esta mortalidade materna e feminina tão elevada nos países menos desenvolvidos deve-se à insuficiência de vigilância e cuidados de saúde, à subalimentação, mas, também, às conseqüências de gravidezes muito precoces em crianças e jovens cujo crescimento não está completo e das mutilações sexuais. Essas mutilações são ainda hoje praticadas em certas comunidades asiáticas, na Índia, Malásia, Indonésia, mas, sobretudo, na África, onde mais de 2 milhões de meninas com idades geralmente compreendidas entre os 4 e os 10 anos de idade são anualmente vítimas destas mutilações dolorosas, que colocam a sua saúde em risco e conduzem, em muitos casos, à morte. Cabe salientar, segundo a OMS e a UNICEF (2003), que no ano de 2000 a taxa de mortalidade materna (mortes durante e em conseqüência do parto) por cada 100 mil nascimentos distribuiu-se da seguinte forma:

- 920 na África Subsaariana; 520 no Centro e Sul da Ásia; 210 no Sudoeste Asiático; 240 na Oceania; 190 na América Latina e Caraíbas; 20 nos países desenvolvidos; 24 na União Européia; 5 em Portugal (Portugal constitui um dos países do mundo e da União Européia com menor taxa de mortalidade materna).

Também é nos países mais pobres que o direito das mulheres e das crianças à educação é o mais desprezado, sendo fundamental o acesso à 
educação das crianças, particularmente das meninas. Muito embora tenha havido ao nível mundial progressos na escolarização feminina, este desenvolvimento é muito desigual segundo as regiões, constituindo as mulheres quase dois terços dos analfabetos do mundo. Dados da UNICEF revelam-nos que 130 milhões de crianças em idade de ir à escola não são escolarizadas nos países em desenvolvimento, sobretudo na África Subsaariana, na Ásia Ocidental e do Sul, sendo que 65\% são meninas, o que tem implicações a diferentes níveis (MARTINETTI, 2002). O analfabetismo constitui um entrave ao desenvolvimento global da criança, criando dificuldades de integração na vida adulta, na compreensão e inserção no mundo, na sua diversidade e complexidade, criando obstáculos à promoção da saúde e bem-estar, à proteção da criança contra as crescentes e múltiplas formas de violência e exploração.

Existe uma relação direta entre educação e taxas de mortalidade, em particular, da mortalidade das crianças de menos de cinco anos. Por exemplo, no estado de Kerala (Sul da Índia), em que a alfabetização é geral, as taxas de mortalidade infantil são as mais baixas dos países em desenvolvimento e as taxas de fecundidade as menos elevadas da Índia. Vários estudos mostram que cada ano a mais de escolarização traduz-se por uma regressão do índice de fecundidade e por um recuo da mortalidade infantil e das mortes ligadas à maternidade, tendo as mulheres instruídas menos filhos e filhos mais saudáveis e mais instruídos do que os das mulheres não instruídas (UNICEF, 1999).

A pobreza e a precariedade social constituem igualmente um fator de risco de delinqüência, de comportamento anti-social e de abandono escolar, particularmente nas zonas degradadas das grandes cidades. As investigações indicam-nos que as taxas mais elevadas de comportamento anti-social e violento são referidas nas classes sociais mais desfavorecidas e que vivem em meio urbano (ELLOTT et al., 1980, 1996; RUTTER et al., 1998). A dureza das condições de vida e o estresse quotidiano em que estas famílias vivem fazem com que tendam a apresentar disfuncionamentos psicológicos e familiares, diversas formas de psicopatologia, não exerçam as competências comunicacionais, de supervisão, controle e autoridade na educação dos filhos. As crianças destas famílias carentes e pobres têm, muitas vezes, modelos anti-sociais e de violência em casa (PATTERSON et al., 1991, 1992).

\section{Mortalidade, Desenvolvimento e SIDA}

Também a SIDA é uma das principais doenças que está na origem das elevadas taxas de mortalidade, nomeadamente na África.

A SIDA tem graves conseqüências sobre a família, afetando profundamente a organização familiar, modificando os papéis familiares, fragilizando 
as economias familiares, criando um conjunto de circunstâncias que originam ou agravam a pobreza das famílias. Esta doença afeta grandemente a economia dos países em desenvolvimento, muito em particular, no continente africano. A SIDA está igualmente na origem de muitas crianças órfãs. Em 2000, estimava-se em 13 milhões o número de crianças cuja mãe, pai ou ambos tinham morrido desta doença, sendo que 95\% dessas crianças viviam na África Subsaariana (UNICEF, 2001). No final de 2002, estimava-se em 29 milhões e 400.000 o número de pessoas infectadas pelo VIH/SIDA só na África Subsaariana. Moçambique é o país lusófono mais afetado pela SIDA, havendo aí mais de 400 mil crianças órfãs que perderam o pai ou o pai e a mãe por causa desta doença. Em 2002, 2,4 milhões de africanos morreram com SIDA, matando esta doença cerca de 6000 pessoas por dia na África, sendo este continente o continente mais afetado (30 milhões de pessoas estão infectadas) e onde já se registraram mais mortes por SIDA (15 milhões). Em todo 0 mundo, estima-se em 42 milhões o número de pessoas que no final de 2002 viviam com VIH/SIDA, sendo 3,2 milhões crianças com menos de 15 anos (ONUSIDA; OMS, 2003).

Para as Nações Unidas (2002), a SIDA poderá fazer recuar a esperança de vida em dezessete anos nos nove países mais pobres em que a prevalência de VIH nos adultos é igual ou superior a 10\%. Se não forem disponibilizados recursos para a prevenção e tratamento dos doentes com SIDA, estima-se que em 2010 haverá, só na África Subsaariana, 20 milhões de crianças órfãs em conseqüência desta doença. A perda parental vai afetar o equilíbrio emocional, o desenvolvimento mental e físico e a saúde destas crianças. Socialmente isoladas e estigmatizadas, estas crianças encontram-se em situação de maior vulnerabilidade, de maior exposição a diferentes riscos e a problemas psicossociais, sanitários e escolares. Privadas da família, de cuidados básicos e de recursos financeiros, obrigadas a tomar conta de si próprias e à mercê de todo o tipo de violência, desinseridas socialmente e descolarizadas, as crianças órfãs da SIDA têm menos oportunidades que as outras crianças de serem vacinadas e de irem à escola, correndo mais riscos de serem mal alimentadas, maltratadas e exploradas, inclusive utilizadas em milícias armadas (UNICEF, 2001).

\section{Violência Familiar, Social e Política}

No que toca à violência familiar, esta constitui uma realidade complexa e multiforme. Para a OMS, 40 milhões de crianças de menos de 15 anos de idade são anualmente vítimas no seu meio familiar de maus tratos e de privação de cuidados essenciais e educativos (UNICEF, 1999). A violência familiar ocorre nas diversas culturas e estratos sociais, sendo as mulheres e as crianças 
as principais vítimas. No entanto, as carências econômicas e o isolamento social, o estresse e as múltiplas frustrações decorrentes da precariedade das condições de vida, das rupturas familiares, das fracas redes de apoio, do abuso de álcool ou drogas, são fatores que agravam as condições de risco, de maus tratos e violência à criança, assim como, os conflitos familiares graves (BIFULCO; MORAN, 1998).

Com efeito, atrás dos conflitos familiares graves, esconde-se freqüentemente a precariedade das condições de vida, tendo a pobreza, o desemprego e a exclusão conseqüências sociais e psicológicas graves sobre as crianças e os adultos. A vergonha, o estresse, a autodesvalorização, a depressão, 0 recurso ao álcool, à violência e à droga contribuem para a deterioração das relações conjugais e com os filhos, condicionam a qualidade do controle parental face ao risco de entrada na adolescência e afetam a saúde mental e física da família e da criança (MALEWSKA et al., 1973; WELLS et al., 1985, 1991; BLECHMAN, 1982; WALGRAVE, 1992). Por exemplo, nos EUA, mais de $50 \%$ das crianças que vivem em contextos sociais e econômicos desfavorecidos estão mais sujeitas a situações de violência física, psicológica e abuso sexual (TAYLOR et al., 1994; OSOFSKY, 1995).

Também a violência política e os conflitos armados têm aumentado, destacando-se entre os vánios fatores os efeitos da globalização. Esta, incrementando a fragmentação e a marginalização de alguns países e grupos, tem alargado as desigualdades e a fragilização das economias e dos direitos sociais, aumentado a concorrência e a luta pela posse de recursos, o que, associada a outros fatores, aumenta a probabilidade de conflitos políticos e a violência.

Os conflitos políticos e armados não só têm vindo a aumentar a violência, a mortalidade, particularmente infantil, o número de refugiados, os traumatismos, a fragmentação das famílias e a fragilização das economias, tocando países já pobres à partida, como na África, como ainda têm afetado grandemente a saúde, desenvolvimento e escolarização das crianças. Com estes conflitos, tem aumentado a utilização e o número de crianças que combatem em forças regulares governamentais ou em grupos rebeldes. Sendo difícil indicar números exatos, a UNICEF adianta, no entanto, o número de 300.000 crianças-soldados, meninos e meninas, em diferentes regiões do mundo, recrutadas, sobretudo, na África Subsaariana, mas também na Birmânia, Sri Lanka, Colômbia, Kosovo e Afeganistão. Moçambique e Angola utilizaram também as crianças para estes fins. As crianças-soldados são recrutadas não só para combaterem, mas, também, para atividades domésticas (cozinheiras) e sexuais (sobretudo as meninas), sendo vítimas de múltiplas formas de violência e de traumatismos físicos e psicológicos graves que afetam a sua saúde física e mental. Essas crianças, recrutadas em países sem sistemas de proteção e segurança, em que a violência, a pobreza e o endividamento é grande, onde 
há falta de meios de sobrevivência para as comunidades e para as famílias, muitas vezes órfãs, para além do sentimento de abandono e exclusão, vêem a guerra, a pertença a um grupo e a posse de uma arma como alternativa de sobrevivência e de segurança. Para os recrutadores, as vantagens são múltiplas, já que as crianças não são remuneradas, não reclamam, sendo mais obedientes e manipuláveis.

\section{Criança, Família e Migração}

O desfasamento crescente entre níveis de desenvolvimento e entre estruturas demográficas de países ricos e pobres, os conflitos políticos e armados têm gerado um número cada vez maior de migrantes e refugiados.

No que se refere às famílias migrantes, estas, separadas do seu grupo social, cultural e familiar, desenraizadas e isoladas, apresentam, muitas vezes, dificuldades psicossociais, emocionais e adaptativas, tendo o isolamento e a pobreza das relações sociais e familiares repercussões diretas nas relações da mãe e da criança e nas respostas educativas, provocando, em certos casos, um empobrecimento e desequilíbrio no sistema de interação mãe-criança e uma inadequação das respostas familiares, em particular maternais, às necessidades da criança. $\mathrm{O}$ confronto com novos contextos, com mudanças físicas, sociais e culturais, com novos modelos, muitas vezes incompreensíveis e contraditórios, a falta de referências culturais sobre as quais se apoiarem e as condições de isolamento e precariedade social em que vivem, tornam freqüentemente as famílias vulneráveis e incapazes de fornecer às crianças um suporte psicológico, afetivo e familiar sólido do qual elas necessitam para se desenvolverem. As mães, encontrando-se, muitas vezes inseguras e em conflito quanto aos cuidados e atitudes face aos seus filhos, deprimidas e isoladas, não encontram em si mesmas, nem no ambiente, os recursos e o suporte necessário para se adaptarem às exigências de um meio estrangeiro, "estranho" e diferente, nalguns casos, abandonando o acompanhamento das crianças aos serviços de saúde e escolares. Algumas investigações mostram uma vulnerabilidade da mãe e do bebê migrante, com um número importante de depressões e psicoses pós-parto da mãe e distúrbios funcionais do bebê, tais como, problemas de sono e alimentação (RAMOS, 1993, 1999, 2001, 2003).

Também as más condições sociais e habitacionais de uma grande parte da população migrante, vivendo em condições de superpopulação, falta de conforto e higiene, associadas a problemas lingüísticos e culturais que dificultam a comunicação com os diferentes profissionais, têm influên- 
cia na qualidade de vida e saúde da família, em particular da criança, estando na origem de patologias várias e aumentando as situações de risco e exclusão. Investigações realizadas na Europa e na América do Norte sobre as crianças migrantes, sobretudo de famílias provenientes de países em desenvolvimento, evidenciam uma taxa mais elevada e um período mais longo de hospitalização, uma maior incidência de patologias infecciosas benignas, como bronquites, pneumonias, infecções respiratórias e intestinais, subnutrição, uma maior patologia acidental (queimaduras, intoxicações, acidentes vários), comparativamente às crianças nacionais. Apresentam igualmente atrasos de linguagem, dificuldades de aprendizagem, insucesso escolar e problemas de adaptação social, sobretudo na adolescência. A essas problemáticas estão associados fatores psicológicos, lingüísticos e culturais, mas são igualmente determinantes a precariedade e a exclusão social e cultural em que vive uma grande parte da população migrante, nomeadamente, as crianças. Como vários estudos demonstram, quanto mais as crianças são excluídas, mais elas têm necessidade de cuidados pediátricos, pedopsiquiátricos e psicológico (RAMOS, 1993, 1997, 1998, 1999, 2001, 2002, 2003).

Também o elevado insucesso escolar das crianças migrantes tem conseqüências psicológicas importantes nas crianças e nas representações que as próprias famílias têm sobre si mesmas e sobre os seus filhos, implicando igualmente a marginalização das crianças, já que estas são excluídas dos circuitos de apropriação dos saberes ou, pelo menos, daqueles que são mais valorizados nas sociedades desenvolvidas.

A escola constituiu para a criança e família migrante um espaço importante de contacto, integração e inclusão na sociedade de acolhimento e desempenha um papel fundamental para a criança e a sua família. As famílias depositam na escola (a qual muitas não conheceram nem freqüentaram) as esperanças e o êxito social não concretizados no país de origem, expectativas que a escola não está, muitas vezes, em condições de oferecer. Com efeito, a escola em que os pais imigrantes depositam confiança, esperança e via para uma profissão e êxito social dos seus filhos não consegue responder a estas expectativas, aparecendo, muito freqüentemente, como elemento de exclusão, de reprodução de estereótipos e preconceitos, de insucesso e de desigualdade, não proporcionando uma efetiva igualdade de oportunidades para os diferentes grupos étnico-culturais aí presentes (BOURDIEU et al., 1970; BERNSTEIN, 1977).

É importante realçar que as modalidades de inclusão das crianças migrantes na escola e na sociedade refletem os próprios modos de inclusão das famílias e dos adultos que as educam, sendo igualmente os processos de socialização determinantes na manutenção das atitudes de discriminação e exclusão. 


\section{Considerações finais}

A saúde, a educação, os comportamentos e as concepções relacionadas com as modalidades de cuidar, de educar, de proteção, implicam um conjunto indissociável de fatores sociais, individuais e familiares, correspondem a um processo complexo e dinâmico a compreender na globalidade do indivíduo, nas suas relações com os diferentes contextos em que está inserido, (contexto ecológico-cultural, socioeconômico, demográfico, familiar, político) nas representações individuais e coletivas, no projeto político vigente na sociedade e na acessibilidade aos serviços de saúde e educação. Como assinala a OMS (1986):

As condições e recursos prévios para a saúde são a paz, um abrigo, a alimentação, um ecossistema estável, um rendimento, os recurso individuais, a justiça social, a equidade. Toda a melhoria ao nível da saúde está obrigatoriamente baseada nestes requisitos fundamentais.

É essencial conhecer os contextos e as condições em que vivem as crianças e as famílias, analisar o modo como essas condições afetam a saúde, o desenvolvimento do indivíduo e a sua capacidade de adaptação e como elas podem ser modificadas, de forma a implementar estratégias e políticas que promovam o potencial de desenvolvimento e a saúde, o bem-estar e a qualidade de vida das crianças e das famílias.

É indispensável implementar políticas e estratégias preventivas e interventivas que tenham em conta as características e necessidades individuais, sociais e culturais das crianças e das famílias, incrementar os equipamentos e serviços de apoio à criança e à família, de modo a que todas as crianças tenham acesso às estruturas sociais, sanitárias e educativas.

É fundamental rever as políticas sociais, familiares, sanitárias e educativas, assim como, desenvolver intervenções que ajudem a fortalecer os fatores de proteção familiar, nomeadamente, que promovam a educação parental, as competências educativas, comunicacionais e de adaptação dos pais, de modo que possam lidar de um modo mais adequado e eficaz com as situações de risco e de estresse.

É importante melhorar a qualidade e dignidade de vida das famílias e das crianças autoctones ou migrantes, promovendo melhores condições de vida, alimentação, habitação, segurança, saúde, educação, integração das famílias e protegendo as crianças das numerosas formas de maus tratos, exploração, violência e exclusão.

É necessária a eqüidade e a solidariedade na resposta às necessidades das crianças e das famílias, de forma que todas as pessoas e grupos 
possam partilhar do desenvolvimento e dos avanços científicos e tecnológicos colocados a serviço da educação, da saúde, da qualidade de vida e bem-estar.

É indispensável promover a educação enquanto um direito e essência de desenvolvimento humano, uma forma de mobilização e transformação social, um elemento fundamental para lutar contra a pobreza, as desigualdades e a discriminação, contra a doença e a mortalidade infantil e materna, um meio de proteção da criança contra as diferentes formas de exploração e um instrumento fundamental de promoção do desenvolvimento.

É essencial trabalhar para que o artigo 3 da Convenção Internacional dos Direitos da Criança (ONU, 1989) se torne uma realidade:

Os Estados comprometem-se a assegurar à criança a proteção e os cuidados necessários ao seu bem-estar, tendo em conta os direitos e deveres dos seus pais, tutores ou de outras pessoas legalmente responsáveis por ela, colocando em prática todas as medidas legislativas e administrativas apropriadas para atingir este objetivo.

Reconhecer e promover os direitos da criança passa, em primeiro lugar, por criar as condições necessárias para que seja possível oferecer-lhe um ambiente social, familiar e educativo apropriado, um sistema sanitário e educativo/pedagógico eficiente, não podendo a satisfação destes direitos ser efetiva, sem uma conscientização e implicação dos responsáveis políticos e cidadãos e sem uma abordagem multidisciplinar e global, destinada a responder às necessidades psíquicas, físicas e sociais da criança desde o início da vida e capaz de transformar a vulnerabilidade, as situações de risco e exclusão, num processo estruturante, dinamizador e inclusivo.

\section{Referências}

ANTHONY, E.; CHILAND, C.; KOUPERNICK, C. L'enfant dans sa famille. L'enfant vulnérable. Paris: PUF. 1982.

.; CHILAND, C. L'enfant dans sa famille. Parents et enfants dans un monde en changement. Paris: PUF. 1983.

BANQUE MUNDIALE (BM). Rapport sur le développement dans le monde 2000-2001. Combattre la pauvreté. Paris: Eska, 2000.

BIFULCO , A.; MORAM, P. Wednesday child. Research into women's experience of neglect and abuse in childhood and adult depression. London: Routledge, 1998. 
BERNSTEIN. B. Class, codes and control. London: Routledge and Kegan Paul, 1997.

BERRY, J. Human ecology and cognitive style. New York: Sage Halsted Wiley, 1976.

, etal. Cross cultural psychology: Research and applications. Cambridge: Cambridge University Press, 1992.

BLECHMAN, E. Are children with one parent at psychological risk? A methodological Review. Journal of marriage and the family. [S.l.], n. 44, p. 179-195, 1982.

BOURDIEU, P.; PASSERON, J. La réproduction. Paris: Minuit, 1970.

BOURGUIGNON, O.; RALU, J.; THERY, I. Du divorce et des enfants. Paris: PUF. 1985.

BRODY, D; et al. Blood lead levels in the US population. Phase 1 of the Third National Health and Nutrition Examination Survey. Journal of the American Medical Association. [S.l.], n. 272, p. 277-283, 1994.

BRONFENBRENNER, U. The ecology of human development: Ex periments by nature and design. Cambridge: Harvard University Press, 1979.

DUBOIS, J. Pauvreté et inégalités: situation et politiques de réduction. In: LERY, A.; Vimard, P. (Coord.). Population et développement: les principaux enjeux cinq ans aprés la Conférence du Caire, n. 12. Paris: Ceped, 2001.

ELLOTT, D.; HUIZINGA, R. Reconciling race and class difference in selfreported and official estimates of delinquency. American Sociological Review, n.45, p. 95- 110, 1980.

ELUOTT, D. et al. The efects of neighborhood disadvantage on adolescent development. Journal of research in crime and delinquency, 33, p. 389426., 1996.

GABARINO, J. Children and families in the social environment. New York: Aldine de Gruyter, 1992.

HUSTON, A.; MCLOYD , V.; COL, C. Children in poverty: issues in contemporary research. Child Development, n. 65, p. 275-282, 1994.

IBGE, Instituto Brasileiro de Geografia e Estatística. Crianças e adolescentes: indicadores sociais. Rio de Janeiro: IBGE. 1991. v. 4-5.

LANGOUET, G. L'état de l'enfance dans les nouvelles familles en France. Paris: Hachette, 1998. 
LOEBER, R. Antisocial behavior: more enduring than changeable? Journal of the American Academy of Child and Adolescent Psychiatry, n. 30, p. 393397, 1992.

LOEBER, R; FARRINGTON, D. Child Delinquents. London: Sage, 2001.

MALEWSKA, H.; PEYRE, V. Délinquance juvenile, familiale, école et société. Vaucresson: CFRES. 1973.

MARTINETTI, F.Les droits de l'enfant. Paris: Flammarion, 2002.

NATIONS UNIES, Rapport mondial sur le développement humain. New York: 1999.

NATIONS UNIES. The world's women 2000. Trends and Statistics. New York: 2000.

OGBU, J. Originis of social competence: a cultural ecological perspective. Child Developpement, n. 52, p. 413-429, 1981.

OMS, Organização Mundial da Saúde. Health promotion: concepts and principles in action, a policy framework. Geneva: OMS. 1986.

OMS, Organisation Mondiale de la Santé.Bridging the Gaps. Geneva: OMS. 1995.

. Rapport sur la santé dans le monde 1998. La vie au XXIe siècle. Une perspective pour tous. Genève: OMS. 1998.

. Rapport sur la santé dans le monde 1999. Pour un réel changement. Genève: 1999.

. Rapport sur la santé dans le monde 2000. Pour un systéme de santé plus performante. Genève: OMS. 2000.

OSOFSKY, J. The effets of violence exposure on youg children. American Psychologist. n. 50, p. 782-788, 1995.

PATTERSON, G.; REID, J.; DISHION, T. Predicting future clinical adjustment from treatment outcome and process variables. Psychological Assessment, $n$. 7, p. 275-285, 1992.

;CAPALDI, D.; BANK, L An early startermodel forpredicting delinquency. In: PEPLER, D.; RUBIN, K. (ed.) The development and treatment of childhood agression. Hillsdale: NJ, Erlbaum, 1991.

PD, Population Division. World Population Prospects, the 2000 Revision. Highlights Nations Unies. New York: PD, 2000. 
PNUD, Programme des Nations Unies pour le Développement. Rapport mondial sur le développement humain 1997. Le développement humain au service de l'éradication de la pauvreté. Paris: Economica, 1997.

. Rapport mondial sur le développement humain 2000. Droits de l'homme et développement humain. Bruxelles: De Boeck Université, 2000.

RAMOS, N. Maternage en milieu portugais autochtone et immigré. De la tradition à la modernité. Une étude ethnopsychologique, 1993. Tese (Doutorado em Psicologia) - Universidade René Descartes, Paris, Sorbonne, 1993.

. Cultura, saúde e desenvolvimento: novos desafios nas políticas social e de saúde. In: WORKSHOP: ETNICIDADE, SAÚDE COMUNTTARIA E POLÚTICA SOCIAL EM PORTUGAL: UMA ABORDAGEM MULTIDISCIPLINAR, 1997, Lisboa. Anais... Lisboa: [S.n.], 1997.

RAMOS, N. Famílias e crianças em situação de risco: da prevenção à intervenção. In: JORNADAS TÉCNICAS: EXCLUSÃO SOCIAL E SOLIDARIEDADE: O LUGAR DAS GERAÇÕES E O PAPELDA SANTA CASA DA MISERICÓRDIA DE LISBOA, 1998, Alcoitão. Anais... Alcoitão: [S.n.], 1998.

. Saúde e multiculturalidade. A criança em contexto migratório. In: CONGERSSO INTERNACIONAL 10.: SAÚDE COMUNITÁRIA E EXCLUSÃO SOCIAL, 1999, Lisboa. Anais... Lisboa: [S.n.], 1999.

. Políticas interculturais e sócio-educativas ao nível da infância e da juventude- Os novos desafios da inclusão e do desenvolvimento. In JORNADAS CIENTIFICAS: DA INSTITUIÇÃO PARA AS PESSOAS, 2001, Lousa. Anais... Lousa: [S.n.], 2001.

. Comunicação, cultura e interculturalidade: para uma comunicação intercultural. Revista Portuguesa de Pedagogia, v. 35, n. 2, p. 155-178, 2001.

. Educação, saúde e culturas. Novas perspectivas de investigação e intervenção na infância. Revista Portuguesa de Pedagogia, v. 36, n. 1-2-3, p. 463-487, 2002.

. Interculturalité, communication et education. Bucareste: Melina, 2003.

RAZKALIAH, N.; EPELBOIN, A. Chroniques du saturnisme infantile - 1989-1994. Enquête ethnologique auprés des familles parisiennes originaires du Sénegal et du Mali. Paris: L'Harmattan, 1997.

RUTTER, M.; GILER, H.; HAGELL, A. Antisocial behavior by young people. Cambridge: Cambridge University Press, 1998. 
. Stress research: accomplishments and tasks aheed. In: HAGGERTY, R. et al. (ed.). Stress, risk and resilience in children and adolescent, processes mechanisms and interventions. Cambridge: Cambridge University Press, 1994.

SHORTER, E. La naissance de la famille moderne. Paris: Seuil, 1997.

SINGLY, F. Sociologie de la famille contemporaine. Paris: Nathan, 1993.

SUPER, C.; HARKNESS, S. The developmental niche: A conceptualization at the interface of child and culture. International Journal of Behavioral Development, n. 9, p. 545-569, 1986.

SUPER, C.; HARKNESS, S. The cultural structuring of child development. In: J. BERRY, P.; DASEN, T. Saraswathi (ORG.). Handbook of cross cultural psychology. Boston: Allyn and Bacon, 1997. v. 2.

TAYLOR, L et al. Witnessing violence by young children and their mothers. Journal of developmental and behavioral pediatrics, n. 15, p.120-123, 1994.

UNICEF. La situation des enfants dans le monde. Genève: 1999 - 2002.

WALGRAVE, L. Délinquance systématisée des jeunes et vulnérabilité sociétale.Essai de construction d'une théorie integrative. Genéve-Paris: Médicine et Hygiène-Méridiens Klincksieck, 1992.

WELLS, L.; RANKIN, J. Broken homes and juvenile delinquency: an empirical review. Criminal Justice Abstracts, v. 17, n. 2, p. 249-272, 1985.

WELLS, L; RANKIN, J. Families and delinquency: a meta-analysis of the impact of broken homes. Social Problems, v. 38, n. 1, p. 71-93, 1991.

WHITING, B.; WHITING, J. Children of six cultures. A psychological analysis. Cambridge: Harvard University Press, 1975.

Recebido em: 24 de novembro de 2005. Aceito em: 19 de dezembro de 2005. 